\title{
Understanding Consumer Responses to Product Risk Information
}

Two experiments examine how message framing moderates consumer responses to product risk information. The findings suggest that contrary to an influential theory, consumers exposed to loss-framed messages exhibit a general aversion to product risk involving both short-term adverse effects and more permanent harm. In contrast, consumers exposed to gain-framed messages differentiate among different types of product risk. They essentially ignore temporary product risks but give considerable decisional weight to risks of permanent harm. This article discusses the implications of these findings for those who design and regulate promotional messages that contain product risk disclosures.

$\mathbf{W}$ ith increasing frequency, consumers are asked to evaluate product risk information (i.e., information that product use may lead to negative consequences). For example, advertisements for tobacco products have long been required to disclose the health hazards associated with their use, and promotional materials for financial investments often contain caveats about potential financial losses (Fitch 1997; Fox et al. 1998). However, the most dramatic growth in advertised product risk disclosures has come from a relatively new category of advertising: directto-consumer (DTC) advertisements for complex medical products. Over the past 15 years, there has been an explosion of such advertising; total expenditures on DTC prescription drug advertising has grown more than 200-fold, from \$12 million in 1989 to more than \$3 billion in 2003 (Calfee 2002; Thomaselli 2004). Most such advertising is required to contain information on product risks. However, as Cohen (2002, p. 172) notes, there is "continuing concern that consumers may not adequately comprehend the benefits and risks of using such highly technical products."

There are two kinds of product risk information that consumers may consider when evaluating such products. First, there are product risk disclosures (i.e., explicit statements of the potential adverse outcomes resulting from product use). For example, Food and Drug Administration rules require that any DTC advertisement that mentions both the name of a prescription drug (e.g., Celebrex) and its function (e.g., treatment of osteoarthritis) must also contain information on product side-effect risk - that is, the possibility of unintended physical harm (ranging from temporary discomfort to permanent disability or even death) resulting

Anthony D. Cox is Professor of Marketing, Kelley School of Business Indianapolis (e-mail: acox@iu.edu), Dena Cox is Professor of Marketing and Eli Lilly Faculty Fellow, Kelley School of Business Indianapolis (e-mail: dcox@iu.edu), and Gregory Zimet is Professor of Pediatrics and Clinical Psychology, School of Medicine (e-mail: gzimet@iupui.edu), Indiana University. A portion of this research was funded by a National Institutes of Health grant (No. R01 Al049644). The authors thank Sue Mantel for her helpful comments on a previous draft of this article. from product use (for discussions of the rules governing such risk disclosures, see Calfee 2002; Menon et al. 2003b).

Second, consumers may also make inferences about the risks of specific products, even when those risks are not explicitly stated. For example, a consumer may perceive that certain product forms (e.g., injections, radiological scanning) entail inherent risks. In addition, a growing number of researchers have suggested that consumers perceive certain product functions (e.g., problem detection) as inherently riskier than others (see Meyerowitz and Chaiken 1987; Rothman and Salovey 1997).

It is important for marketers and policy makers to understand how consumers evaluate product risk information. Unfortunately, research on this topic has yielded inconsistent findings. Some studies suggest that information on product risks lowers consumers' product evaluations (e.g., Morris, Mazis, and Brinberg 1989; see also Goetzl 2001); however, others suggest that consumers frequently ignore product risk information (e.g., Menon et al. 2003a), and still others suggest that product risk information can actually enhance consumers' product evaluations (e.g., Goetzl 2000; Rodale Publications 1999).

In an effort to explain these contradictory findings, the current study proposes a potential contingency variable that may moderate the effect of product risk information on consumers' product evaluations: message framing. Any promotional message can stress either the potential gains from adopting a behavior or the potential losses from not adopting it. For example, a loss-framed advertisement promoting flu vaccinations would stress the potential health costs of not getting vaccinated (e.g., getting influenza), whereas a gain-framed advertisement would stress the protective benefits of getting vaccinated (e.g., avoiding influenza). Although these two messages might contain the same essential information, research suggests that they elicit different consumer responses (for a review of framing research, see Levin, Schneider, and Gaeth 1998). Relevant to the current study, there are theoretical reasons to believe that message framing may moderate how consumers respond to product risk. 
Function/risk theory (e.g., Meyerowitz and Chaiken 1987; Rothman and Salovey 1997) draws on Kahneman and Tversky's (1979) prospect theory to suggest that negatively framed messages increase consumers' willingness to use high-risk products (particularly those with a problem detection function), whereas positively framed messages increase the attractiveness of low-risk products. In contrast, other theories (e.g., Adaval 2001; Isen 2000; Yuen and Lee 2003) seem to suggest the opposite, positing that consumers exposed to positive, upbeat stimuli should be more willing to tolerate certain types of product risks, whereas those exposed to negative stimuli should exhibit greater aversion to such risks.

This article examines these theories and discusses their (sometimes conflicting) implications for understanding how consumers evaluate product risk. Specifically, we address three central research questions:

1. How do consumers assess product risk? Specifically, how are product risk perceptions influenced by both explicit product risk disclosures and information on product function (e.g., problem prevention versus problem detection).

2. How do consumers weigh perceived product risks in forming overall product evaluations?

3. How are the weights given to product risks influenced by message framing?

In the following sections, we discuss previous research and theory relevant to these questions. Then, we report the results of two experiments that examine these issues empirically. Finally, we discuss the implications of our findings and provide directions for further research.

\section{Effects of Product Function on Perceived Product Risk}

Several researchers have suggested that consumers perceive detection products as inherently risky. Meyerowitz and Chaiken (1987) first introduced the function/risk hypothesis in the context of breast self-examination (BSE). They noted (p. 89), "In the short run, BSE is a risky behavior... [It] requires that a woman risk aversive consequences in the present (e.g., finding a lump, experiencing anxiety) in hopes of enhancing future outcomes.... Of course, in the long run, not performing BSE clearly entails risks (e.g., failing to detect a malignancy). However, because of their temporal remoteness, such longer-term considerations may be less salient than short-term considerations." More recently, Rothman and Salovey (1997) reiterated the link between product function and perceived risk, stating that detection products are considered inherently risky because "one runs the risk of receiving significant, unpleasant information" (p. 5), whereas prevention products (e.g., sunscreen, vaccines) are considered low risk because their "salient function ... is to provide a relatively certain, desirable outcome" (p. 11).

The hypothesized link between product function and perceived risk is argued persuasively in these articles and has gained widespread currency among persuasion researchers and practitioners (as we discuss subsequently). However, closer examination reveals problems with this hypothesis. First, proponents of function/risk theory suggest that consumers view adopting detection behaviors as more risky than not adopting them. However, as Levin, Schneider, and Gaeth (1998) note, this assumes that consumers ignore the long-term risks of not being screened (e.g., allowing a tumor to grow) and focus solely on short-term risks. The finding that consumer disease anxiety tends to increase screening behavior, not decrease it (McCaul et al. 1996), suggests that many consumers adopt a longer-term perspective on detection behaviors.

Second, although some detection products have shortterm risks, so do many prevention products. Many people avoid flu shots for fear of pain and side effects (Centers for Disease Control and Prevention 1995); many women do not push condom use for fear of partners' reactions (Darroch and Frost 1999). If consumers focused only on short-term outcomes, they would view these preventive products as risky.

Finally, there is little empirical evidence that risk perceptions vary with product function. Several studies have examined consumer response to products differing in function (e.g., Rothman et al. 1999; Rothman et al. 1993), but none has shown that detection and prevention products differ in perceived risk.

\section{Effects of Message Framing on Consumer Response to Product Risk}

Another tenet of function/risk theory is that loss-framed messages make consumers more likely to adopt high-risk (e.g., detection) products, whereas gain-framed messages increase the attractiveness of low-risk (e.g., prevention) products. In reviewing previous framing studies, Rothman and Salovey (1997) note that loss-framed messages seem to be more persuasive in studies involving detection products, whereas gain-framed messages seem to be more effective in studies involving prevention products. To explain this apparent difference, they note that prospect theory (Tversky and Kahneman 1981) suggests that consumers prefer riskier options when outcomes are framed as losses but prefer lowrisk options when outcomes are framed as gains (see also Meyerowitz and Chaiken 1987, p. 501). Thus, they conclude that loss-framed messages will persuade people to adopt detection (and other risky) products and that gainframed messages will persuade people to adopt prevention (and other low-risk) products.

This hypothesis is compelling and, if valid, has important marketing implications. It suggests that marketers promoting prevention products (e.g., vaccinations) should use gain-framed messages, whereas those promoting detection behaviors (e.g., HIV testing) should use loss-framed messages. More broadly, it suggests that any product that consumers perceive as risky is most effectively promoted with loss-framed messages.

This theory has become increasingly influential among both persuasion researchers and practitioners. Rothman and Salovey's (1997) article has been cited more than 100 times (Thomson 2004), and the function/risk hypothesis is becoming established doctrine among social marketers (see, e.g., Arkes 2004; Ferguson et al. 2003). However, despite increasing acceptance of this hypothesis, there are unre- 
solved questions about both its empirical support and its theoretical foundation. First, although some studies find loss framing more persuasive in promoting detection and find gain framing more persuasive in promoting prevention, other studies find just the opposite. For example, Robberson and Rogers (1988), Homer and Yoon (1992), and Blanton and colleagues (2001) all find loss framing more effective in promoting prevention behaviors (exercise, mouthwash, and condoms, respectively).

Second, in most studies cited to support function/risk theory, function is confounded with other product traits. For example, mammograms and sunscreen differ not only in function but also in the problems they address, cost, discomfort, and so forth. If framing effects differ between these two products, which of these product traits accounts for the difference? The only study to manipulate product function while holding other product attributes constant (Rothman et al. 1999, Study 1) does not find the predicted two-way interaction between function and framing.

Third, the function/risk hypothesis has theoretical problems. Assume that consumers view detection as high risk and prevention as low risk. Does the function/risk hypothesis then follow logically from prospect theory? Indeed, Tversky and Kahneman (1981) find that when outcomes were framed as losses, consumers preferred the riskier of two options. However, Tversky and Kahneman use "risk" to mean increased variance of potential outcomes; therefore, the riskier options in their experiments had both greater upside potential and greater downside potential than the norisk (or certain) options. Given this definition of risk, choosing a risky option seems more reasonable. Prospect theory posits that people abhor a certain loss (e.g., with Option A, there is a definite loss of \$2,000) and thus are so attracted to the upside potential of complete loss avoidance (e.g., Option B provides a 50\% chance to lose nothing) that they are willing to tolerate the downside potential of even greater losses (e.g., a 50\% chance of losing \$4,000).

In contrast, when function/risk theorists argue that detection behaviors are risky, they use risk to mean an increased possibility of negative outcomes (or what Tversky and Kahneman call downside risk). Consumers who adopt detection behaviors are said to expose themselves to the possibility of short-term psychological loss (e.g., learning they have cancer), whereas nonadopters completely avoid such short-term loss potential. Thus, if the function/risk theorists' assumption that consumers focus solely on shortterm outcomes is accepted, adoption of a detection behavior must be viewed as a kind of psychological Russian roulette, in which consumers actually seek potential short-term losses, with little thought to detection's long-term benefits. Such loss-seeking behavior is antithetical to the tenets of prospect theory.

\section{Alternative Theories of Framing and Risk: Valence Congruency and Risk Discrimination}

Whereas function/risk theory posits that consumers exposed to loss-framed messages actually seek short-term product risks, we propose two alternative theoretical formulations that suggest essentially the opposite: Loss-framed messages induce risk aversion, whereas gain-framed messages increase consumers' tolerance of at least some types of product risk. These two theories (valence congruency and risk discrimination) both rest on two key findings.

First, there is evidence that message framing influences consumers' moods, particularly positive moods. In depth interviews, Cox and Cox's (2001) respondents reported positive, optimistic feelings after exposure to gain-framed messages that promoted mammography and less positive moods after exposure to equivalent loss-framed messages. Similarly, Meyerowitz and Chaiken (1987, p. 506) find that gain-framed respondents were significantly more likely to report feeling "reassured." Thorsteinson and Highhouse (2003) find that respondents exposed to gain-framed want ads reported more positive scores on the Associative Valence index (e.g., "hopeful," "confident," "optimistic") than those exposed to loss-framed messages. Perhaps this finding is not too surprising, because gain-framed messages depict happy endings (in which people do the right thing and, consequently, win money, live long lives, and so forth) and loss-framed messages depict unhappy endings (in which people miss opportunities, lose money, get sick, and so forth.) However, the potential emotional impact of message framing has received remarkably little attention in the framing literature, which has tended to adopt the cognitive emphasis of behavioral decision theory (cf. Loewenstein et al. 2001).

Second, considerable research suggests that consumers exposed to affectively positive stimuli are more willing to tolerate at least some product risk to take advantage of product benefits. However, this literature contains two schools of thought that disagree on whether positive moods increase consumer tolerance of all kinds of risk or simply make consumers more likely to disregard relatively small "low-stakes" product risks.

The valence congruency theory suggests that consumers in positive moods tend to give less decisional weight to all negative product information (e.g., product risks) than consumers in negative moods. This hypothesis is often explained in terms of information priming, in which prior exposure to affectively negative material is theorized to increase the accessibility of potential negative consequences (i.e., risk) in memory, whereas exposure to affectively positive material decreases accessibility of potential negative consequences. For example, Pietromonaco and Rook (1987, p. 400) theorize that negative affect "may influence the perceived likelihood of unpleasant events because it increases the accessibility of previous similar experiences and thus facilitates imagining other potential negative outcomes."

Several studies have produced results that appear to be consistent with the valence congruency hypothesis, such that respondents in positive moods exhibit greater risk tolerance (e.g., Deldin and Levin 1986; Pietromonaco and Rook 1987; Yuen and Lee 2003). However, as Isen (2000) observes, many of these studies presented behavioral risks that were relatively minor (e.g., temporary or minor embarrassment, a small or hypothetical bet). In contrast, in tasks involving high stakes, respondents in positive moods often exhibit 
considerable caution regarding potential risks (see, e.g., Isen and Geva 1987). Therefore, Isen (2000) and Isen and Geva (1987) propose a more complex theory of affect and risk taking, which can be labeled risk discrimination theory. According to this theory, consumers in positive moods are better able to discriminate between important, high-stakes risks and more minor, low-stakes risks. Therefore, consumers in positive moods are more likely to disregard relatively trivial risks than are consumers in negative moods, but they may be reluctant to take large risks. In a sense, consumers in good moods are hypothesized to weigh risks more appropriately in proportion to their relative importance.

Several studies appear to support this theory (for a review, see Isen 2000). For example, in an experiment involving gambling behavior, Isen and Geva (1987, p. 145) find that "when stakes were high,... positive affect subjects were more cautious, whereas when stakes were low, positive affect subjects were more prone to take risks." Several writers have suggested that this phenomenon is part of a broader pattern, in which respondents in positive moods are simply better decision makers (i.e., they are better able to weigh and integrate information rationally and to distinguish the relevant from the irrelevant). For example, Isen (2000, p. 423) states that "positive affect promotes effective thinking about even negative material, if doing so is useful and necessary, even though it also leads people to sidestep unnecessary consideration of undesirable material. This is yet another way in which positive affect promotes flexible problem solving."

In contrast, negative affect is hypothesized to inhibit appropriate weighing of costs and benefits. In the words of Leith and Baumeister (1996, p. 1251), "negative affect apparently inhibits people from considering the affective consequences of possible actions ... [and may induce] poor choices in situations in which there is a long-term [versus] short-term tradeoff."

\section{Hypotheses}

Our first two hypotheses challenge two central tenets of function/risk theory: (1) that consumers perceive detection products as inherently riskier than prevention products and (2) that product function (detection versus prevention) moderates the persuasive effects of message framing. As we discussed previously, the theoretical and empirical bases for these tenets appear questionable. Therefore, our first two hypotheses are null or "theory refutation" hypotheses:

$\mathrm{H}_{1}$ : Product function per se does not influence perceived product risk; that is, consumers do not perceive disease detection products as inherently riskier than prevention products that have the same product form, usage experience, and side effects.

$\mathrm{H}_{2}$ : Product function per se does not moderate the persuasive effects of message framing; that is, message-framing effects do not differ between detection products and prevention products that have the same product form, usage experience, and side effects.

The next two hypotheses are based on our discussion of the valence congruency and risk discrimination theories. As we noted previously, both theories predict that message framing moderates how consumers respond to potential product risks but not in the manner predicted by function/ risk theory. Consistent with both the valence congruency and the risk discrimination theories, but contrary to function/risk theory, we hypothesize the following:

$\mathrm{H}_{3}$ : Consumers exposed to gain-framed messages exhibit less aversion to temporary product risks (i.e., those involving the potential for temporary negative effects) than consumers exposed to loss-framed messages. Consumers exposed to gain-framed messages respond less negatively to a disclosure of such temporary product risk and give less weight to perceived product risk in forming overall product evaluations than consumers exposed to lossframed messages.

However, as we noted previously, the valence congruency and risk discrimination theories diverge on how framing influences the relative weight that consumers give to minor product risks (e.g., the risk that product use may cause temporary unpleasant effects) versus more serious product risks (e.g., the risk that product use may cause permanent harm). Valence congruency theory suggests that exposure to positive, gain-framed information should decrease the weight given to all product risks, large and small. In contrast, risk discrimination theory suggests that exposure to gain-framed messages should enhance consumers' ability to assess the emotional impact of different types of risks accurately and therefore cause them to give greater weight to serious risks than to smaller risks. Because risk discrimination has been better able to explain the range of previous empirical results, we base $\mathrm{H}_{4}$ on this theory:

$\mathrm{H}_{4}$ : Message framing influences the relative weight that consumers give to product risks involving temporary versus permanent adverse consequences. Consumers exposed to gain-framed messages give significantly more decisional weight to permanent product risks than to temporary product risks. In contrast, consumers exposed to loss-framed messages respond equally negatively to both types of product risk.

\section{Study 1}

\section{Product Context and Participants}

We examined our first three hypotheses in the context of skin cancer detection and prevention products. Skin cancer is the most common and one of the most rapidly growing forms of cancer. In 2002, there were 54,200 cases of skin cancer in the United States alone, and 7600 Americans died from the disease (American Cancer Society 2004).

A primary target audience for promoting skin cancer prevention and detection behaviors is young adults, a group that is especially likely to engage in behaviors (e.g., sun bathing, other outdoor recreational activities) that increase lifetime skin cancer risk. Therefore, the participants for this study were young adults whom we recruited from undergraduate business classes at a large urban university in the midwestern United States.

\section{Experimental Design and Stimuli}

In designing this experiment, we attempted to minimize some of the methodological problems that have plagued 
prior research on product function and risk. Specifically, in most prior studies, product function has been confounded with other product differences, such as cost, discomfort, frequency of use, and so forth. To address this problem, we developed gain- and loss-framed print advertisements for two product concepts that differ in function (detection versus prevention) but address the same underlying problem (skin cancer) and involve equivalent usage experience.

\section{Pretest}

Purpose. In the pretest, we attempted to test participants' comprehension of the message-framing and product function message components and to confirm that message framing serves as a mood manipulation. Perdue and Summers (1986) suggest that such manipulation checks are best conducted in a separate pretest rather than included in the "main" experiment that examines the dependent variables (e.g., brand attitudes, intentions). They note (p. 319) that "including these checks in the main experiment can present problems independent of whether they come before or after the dependent variable measures." Manipulation checks placed before the dependent measures may bias the latter (e.g., by creating demand effects), whereas manipulation checks placed after the dependent measures may fail to detect stimulus effects that are inherently transient, such as mood inductions (see, e.g., Vastfjall 2002). Therefore, we conducted a separate pretest to test the effects of our manipulations.

Method. We recruited 70 participants (37 male and 33 female) from undergraduate business classes. Each participant was assigned randomly to one of four experimental advertisements, which varied in behavioral function (prevention versus detection) and message framing (gain framed versus loss framed). Each advertisement had the same picture (a stylized picture of the sun) and headline ("Important News for Young Adults About Skin Cancer"). The body of each advertisement contained three components: (1) basic information about skin cancer (drawn from the American Cancer Society Web site), which was identical for all experimental groups; (2) one of two skin cancer protection product concepts that differed in function (prevention versus detection) but had the same product form and usage experience (both were lotions applied in a doctor's office that were described as "highly effective and very safe"); and (3) an advocacy message that urged consumers to adopt the product, which was either gain framed or loss framed.

After message exposure, pretest participants responded to manipulation checks for perceived product function, message framing, and mood. As a framing manipulation check, respondents used seven-point Likert scales to report whether they believed the message "emphasized the benefits of using the product" or "emphasized the costs of not using the product." As a product function manipulation check, participants reported agreement that "the lotion helps prevent skin cancer" and "the lotion helps detect skin cancer."

We measured postexposure mood using scales we adapted from the work of Howard, Gengler, and Jain (1995) and Meyerowitz and Chaiken (1987). On seven-point Likert scales, each respondent reported the degree to which 14 adjectives (e.g., assured, cheerful, afraid, happy, troubled) described his or her mood state. These responses were entered into a principal components analysis with a Varimax rotation. After the elimination of some items because of high cross-loadings, the final analysis extracted two interpretable factors with eigenvalues greater than one, which together explained $75 \%$ of the variance in the individual items. The first factor captured participants' hopefulness or optimism; items loading on this factor were "hopeful," "cheerful," "assured," and "happy." The second factor tapped into participants' anxiety mood state; items loading on this factor were "afraid," "disturbed," "troubled," and "worried." All loadings were greater than .75, and all crossloadings were less than .15. Next, we constructed two summed scales based on the items loading on these two factors. The hopefulness mood scale had a coefficient alpha value of .84 , and the anxiety mood scale had an alpha value of .92. These two summed scales were not significantly correlated with each other, suggesting that hopefulness and anxiety represent two distinct emotional dimensions, not simply different ends of the same continuum.

Pretest results. When asked whether the message communicated the "benefits of product use," participants exposed to the gain-framed version were slightly more likely to agree $(\mathrm{X}=5.58)$ than those exposed to the lossframed version $(X=5.07)$; however, this difference did not reach statistical significance $(\mathrm{F}=2.69, p=.11)$. However, when asked more specifically if the advertisement "emphasized the costs of not using the product," participants in the loss-framed condition were much more likely to agree ( $\mathrm{X}=$ 5.27) than those in the gain-framed condition $(X=4.06 ; \mathrm{F}=$ $11.9, p<.001)$. This latter finding indicates that the participants comprehended the framing of the messages.

Participants exposed to the prevention product concept were much more likely to agree that the "lotion helps prevent skin cancer" ( $\mathrm{X}=4.90)$ than those exposed to the detection product concept $(\mathrm{X}=3.11 ; \mathrm{F}=15.5, p<.001)$. Likewise, participants exposed to the detection product were much more likely to agree that the "lotion helps detect skin cancer" ( $X=5.97)$ than those exposed to the prevention product $(\mathrm{X}=3.04 ; \mathrm{F}=60.0, p<.001)$.

The pretest also confirmed that consumers experience more positive moods after exposure to gain-framed messages than after exposure to loss-framed messages. Participants exposed to the gain-framed message reported significantly higher levels of hopefulness $(X=3.88)$ than those exposed to the loss-framed message $(\mathrm{X}=2.98 ; \mathrm{F}=8.9, p=$ $.004)$. There was no significant difference in the reported anxiety level of the two message-framing groups.

\section{Main Experiment}

Purpose of study. This experiment has three main purposes. First, it tests $\mathrm{H}_{1}$, that contrary to function/risk theory, disease detection products are not perceived as inherently riskier than prevention products involving the same disease, product form, and usage experience. Second, it tests $\mathrm{H}_{2}$, that the persuasive effects of message framing do not vary with product function. As we noted previously, function/ risk theory posits that loss-framed messages are most persuasive when advocating detection behaviors, whereas gain- 
framed messages are most persuasive when advocating prevention behaviors. However, we argue that the theoretical rationale for this hypothesis (ostensibly based on prospect theory) is problematic and that the empirical evidence in support of it is inconclusive (in part because in most studies, product function is confounded with other product differences). Thus, this experiment attempts to provide a rigorous test of the proposed interaction between function and framing, independently manipulating message frame and product function while holding other variables constant. Third, the experiment examines $\mathrm{H}_{3}$, that consumers exposed to gain-framed messages exhibit less aversion to temporary product risks (i.e., those involving the potential for temporary negative effects) than consumers exposed to lossframed messages. To test this hypothesis, the experiment manipulates product risk independent of product function.

Sample. We recruited 282 young adults from undergraduate business classes at a large urban university in the Midwest. The sample was $41 \%$ female and had a median age of 22.5 years.

Design and stimuli. The experiment used a $2 \times 2 \times 2$ between-subjects factorial experimental design. The factors were message framing (gain framed versus loss framed), product function (prevention versus detection product), and product risk disclosure (presence versus absence of temporary side-effect risk). The manipulation of framing and function were identical to the pretest. We varied product risk disclosure by having the messages state either that the lotion is "very safe" or that the lotion was "generally safe" but in some patients could cause a temporary skin rash that could last for several weeks. Because a product's side-effect profile (i.e., its potential for unintended physical discomfort or harm to the product user) is conceptually distinct from its function (its core purpose or stated customer benefit), this manipulation enabled us to vary product risk independent of product function.

We randomly assigned participants to one of eight experimental advertisements. Each advertisement had the same picture, headline, and basic information about skin cancer as described in the pretest. These were followed by two paragraphs, which contained the experimental manipulations: (1) a paragraph that described one of four skin cancer protection product concepts (a low-risk prevention product, a risky prevention product, a low-risk detection product, or a risky detection product) and (2) a message, which was either gain framed or loss framed, that urged consumers to adopt the product (examples of the experimental messages appear in the Appendix). Test booklets containing the eight experimental messages were randomly assigned to participants within each classroom.

Measures. We assessed perceived product risk by having participants report their agreement on seven-point Likert scales with a series of statements regarding the potential negative consequences of product use: "Using this lotion is risky," "This lotion can lead to bad results," "Using this lotion would make me feel anxious," and "Using this lotion would cause me to worry." We combined participants' scores on these four items to form a mean scale with a coefficient alpha of .77. We assessed overall product evaluation by having participants report their agreement on sevenpoint Likert scales with the following statements: "Overall, I think this lotion is a very good product," "People who use this lotion will be safer than those who don't," "I would rather use this lotion than any currently available alternative," and "Using this lotion would be important to me." We combined these items to form a mean scale with a coefficient alpha of .76. We assessed behavioral intentions by having participants report on seven-point bipolar scales, anchored by "very likely" and "very unlikely," their intention to engage in three behaviors involving the target product: asking their doctor about the product, purchasing the product, and using the product. We combined these to form a mean scale with a coefficient alpha of .90. Finally, participants provided demographic information (e.g., gender, age, education) and reported on their previous skin cancer prevention behaviors (e.g., use of sunscreen) and risk factors (e.g., sun exposure, severe sunburns, family history).

Results. We examined perceived product risk with an analysis of variance (ANOVA), in which perceived product risk was the dependent variable and framing, product risk disclosure, and function were dichotomous factors. As we predicted in $\mathrm{H}_{1}$, there was no evidence that participants perceived detection products as inherently riskier than prevention products. Product function had no impact on perceived product risk $(\mathrm{F}=.24, p=.63)$. The mean perceived risk of the detection product $(\mathrm{X}=3.60)$ was virtually identical to that of the prevention product $(\mathrm{X}=3.53)$. Thus, we found support for $\mathrm{H}_{1}$.

However, there was a strong main effect of the sideeffect manipulation on perceived product risk $(\mathrm{F}=24.9, p<$ $.001)$. Participants in the side-effects disclosure condition perceived significantly greater product risk $(X=3.9)$ than those in the no-side-effects condition $(X=3.2)$.

Message framing did not have significant main or interactive effects on participants' perceptions of product risk level. However, as we discuss subsequently, message framing altered the weight that participants gave to such risk perceptions in forming overall product evaluations.

Overall product evaluations. Next, we conducted an ANOVA that evaluated the effect of message framing, product function, and product risk disclosure on participants' overall product evaluations. Consistent with $\mathrm{H}_{2}$, there was no interaction between message framing and product function $(\mathrm{F}=.03, p=.87)$.

However, framing moderated the impact of the product risk disclosure on participants' overall product evaluations (see Figure 1). As we predicted in $\mathrm{H}_{3}$, there was a statistically significant interaction between message frame and product risk disclosure $(\mathrm{F}=11.19, p=.001)$. To understand this significant interaction better, we analyzed the simple effects of the product risk disclosure in each of the two framing conditions (see, e.g., Keppel 1982, pp. 214-19). This analysis revealed that consumers exposed to loss-framed messages rated the risky (temporary side effects) product significantly more negatively $(X=4.08)$ than the low-risk (no side effects) product $(\mathrm{X}=4.77 ; \mathrm{F}=13.17, p<.001)$. In contrast, in the gain-framed condition, consumers' product evaluations did not differ between the risky product $(\mathrm{X}=$ $4.40)$ and the low-risk product $(\mathrm{X}=4.20 ; \mathrm{F}=1.20, p=.27)$. 
To examine further how message framing affects consumers' sensitivity to product risk, we examined whether the correlation between perceived product risk and overall product evaluations varied significantly between the gainand loss-framed conditions (for a similar analysis, see Pietromonaco and Rook 1987). This analysis revealed that among participants exposed to loss-framed messages, overall product evaluations were negatively correlated with perceived product risk $(\mathrm{r}=-.31, p<.001)$. However, among participants exposed to gain-framed messages, overall product evaluations were not significantly correlated with perceived product risk $(\mathrm{r}=-.07, p=.38)$. A Fisher $\mathrm{r}-\mathrm{to}-\mathrm{z}$ transformation (Kleinbaum and Kupper 1978, pp. 106-107) confirmed that the correlation between perceived product risk and overall product evaluation was significantly different across the two framing conditions $(\mathrm{z}=2.04, p<.05)$. This analysis provides further evidence that participants exposed to gain-framed messages gave less evaluative weight to the product's risks than did those exposed to lossframed messages.

Behavioral intention. Next, we conducted an ANOVA in which behavioral intention was the dependent variable and message framing, product function, and product risk disclo-

\section{FIGURE 1}

\section{Study 1: Effect of Stated Product Risk on Overall Product Evaluations: Gain-Framed Versus Loss- Framed Conditions}

\section{Product \\ Evaluation}

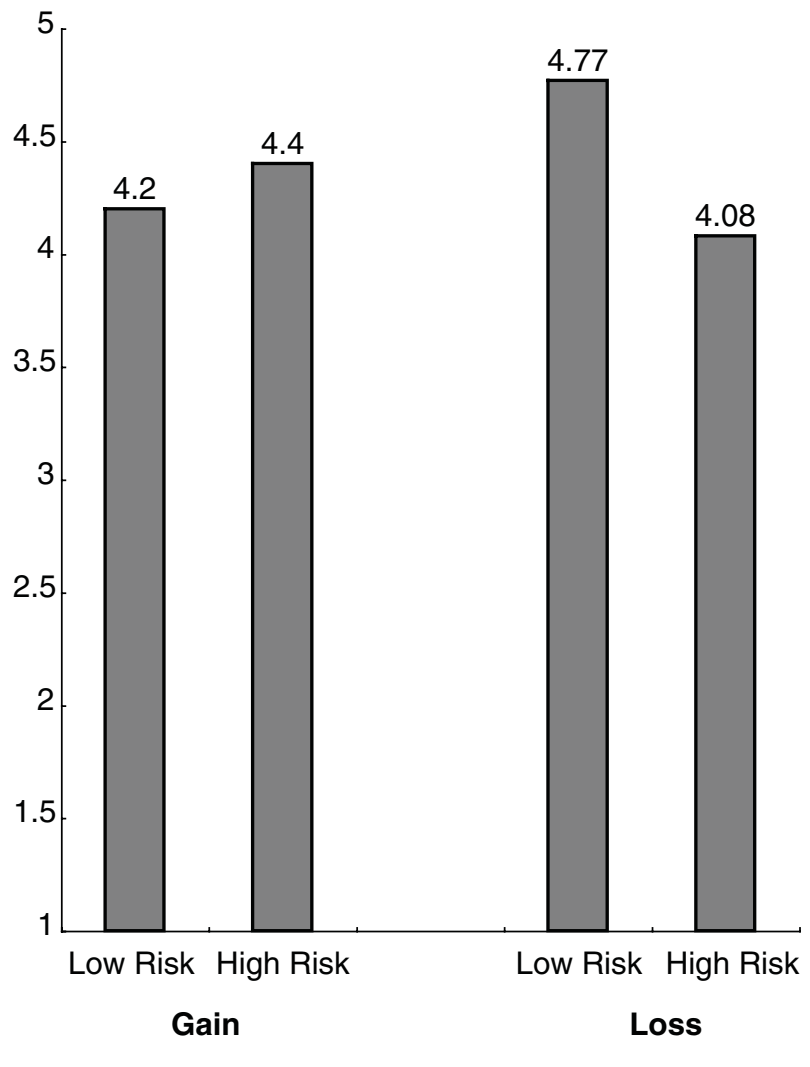

sure were dichotomous factors. As we predicted in $\mathrm{H}_{2}$, there was no interaction between product function and message framing $(\mathrm{F}=1.92, p=.17)$. However, there was a significant interaction between product risk disclosure and message framing $(\mathrm{F}=4.80, p<.05)$. Tests of simple effects revealed that participants in the loss-framed condition reported significantly greater intention to adopt the low-risk product $(\mathrm{X}=4.50)$ than the risky product $(\mathrm{X}=3.75 ; \mathrm{F}=$ $6.58, p=.01)$. Among participants in the gain-framed condition, there was no significant difference in behavioral intention toward the risky $(\mathrm{X}=4.17)$ and low-risk $(\mathrm{X}=$ 4.03) products $(\mathrm{F}=.25, p=.62)$ (see Figure 2$)$.

Next, we conducted mediation analysis to determine whether within the loss-framed condition, the effect of risk disclosure on behavioral intention was mediated by overall product evaluation. We used Baron and Kenny's (1986) mediation test method, estimating a series of regression models and testing the significance of the (unstandardized) regression coefficients. First, a bivariate regression model confirmed that risk disclosure had a significant impact on the overall product evaluation $(\mathrm{B}=-.693 ; \mathrm{t}=-3.68, p<$ $.001)$. Second, a bivariate regression model confirmed that risk disclosure had a significant effect on behavioral intention $(\mathrm{B}=-.745 ; \mathrm{t}=-2.5, p=.01)$. Third, we regressed

FIGURE 2

Study 1: Effect of Stated Product Risk on Behavioral Intention: Gain-Framed Versus Loss-Framed Conditions

\section{Behavioral \\ Intent}

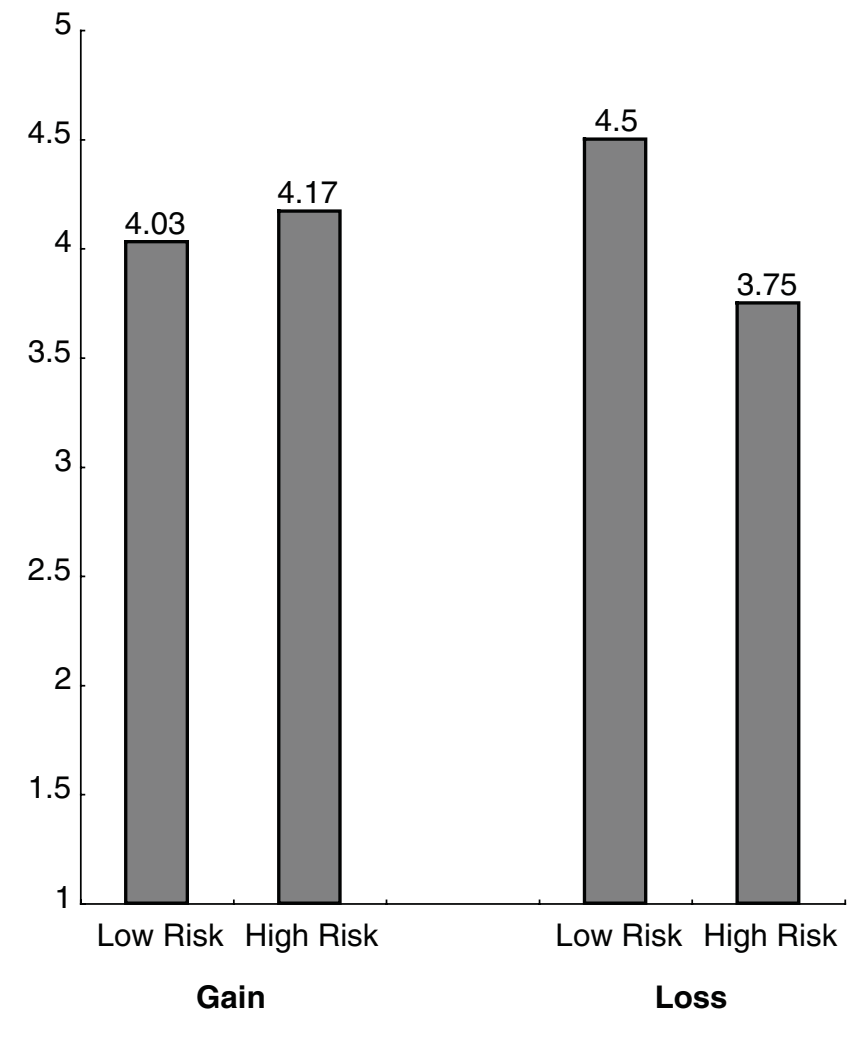


behavioral intention simultaneously on both product risk disclosure and product evaluation. This analysis revealed that the proposed mediator (product evaluation) had a significant influence on behavioral intention $(\mathrm{B}=.986 ; \mathrm{t}=$ $9.35, p<.001)$, whereas the effect of the independent variable (risk disclosure) became nonsignificant $(\mathrm{B}=-.06 ; \mathrm{t}=$ $-.25, p=.80$ ) when the mediator was controlled. Thus, our analysis meets all four of Baron and Kenny's criteria to establish that the effect of risk disclosure on behavioral intention is completely mediated by product evaluation. Finally, Sobel's (1982) test confirmed the statistical significance of the indirect effect of risk disclosure on intention mediated by product evaluation $(\mathrm{z}=-3.43, p<.001)$.

\section{Discussion of Study 1}

Study 1 shows that consumers exposed to loss-framed messages exhibit a greater aversion to a temporary product risk (i.e., involving potential temporary negative outcomes) than do consumers exposed to gain-framed messages (who gave essentially zero decisional weight to such product risks). This finding is contrary to function/risk theory, which states that loss-framed messages induce risk-seeking behavior, but is consistent with both valence congruency theory and risk discrimination theory. However, Study 1 does not indicate whether gain-framed messages increase consumers' tolerance for all risks (as would be predicted by valence congruency theory) or simply minor, temporary risks (as predicted by risk discrimination theory). Not only is this difference theoretically interesting, but it may also have important marketing and public policy implications. If gain-framed messages cause consumers to disregard all product risk information, such messages might (intentionally or unintentionally) result in imprudent decisions about products entailing serious risks (which, as we noted previously, are increasingly being marketed directly to consumers). Conversely, if gain-framed messages merely cause consumers to disregard minor, temporary risks in the pursuit of longterm health benefits, such messages might actually help consumers make more rational decisions to protect their long-term health.

Given the importance of this issue, we address it in a second study, which examines the impact of message framing on consumers' responses to two kinds of product risk: the risk that product use may cause temporary unpleasant effects versus the risk that product use may cause permanent serious harm.

\section{Study 2}

\section{Purpose}

Study 2 serves two main purposes. First, it enables us to replicate the test of $\mathrm{H}_{3}$ (that consumers exposed to gainframed messages give less weight to temporary product risks than consumers exposed to loss-framed messages) in a completely different product context. Second, it enables us to test $\mathrm{H}_{4}$ (that message framing influences the relative weight that consumers give to product risks involving temporary versus permanent adverse consequences).

\section{Product Context}

This study examines the effects of message framing and perceived product risk in the context of hepatitis $B$ virus (HBV) vaccination adoption. Hepatitis B is a serious viral infection of the liver, which can lead to chronic hepatitis and, in some cases, death. It is transmitted in a manner similar to HIV (e.g., through unprotected sex, sharing of needles). However, the risk of HBV infection (unlike HIV) can be greatly reduced by the use of an effective vaccine, ideally administered in a series of three doses (Krugman and Stevens 1994). Unfortunately, many sexually active adults decline the vaccine, even when it is offered for free (Weinstock et al. 1995). Therefore, increased adoption of the HBV vaccine is a major social marketing goal in both the United States and other countries.

\section{Overview of Study Design}

The study is a randomized experiment. We recruited volunteers from the patient populations at three public sexually transmitted disease (STD) clinics located in two large midwestern cities, and we randomly assigned them to treatment conditions that included either gain-framed or loss-framed messages advocating the $\mathrm{HBV}$ vaccination. Because $\mathrm{HBV}$ is an STD, clinic patrons are a prime target audience for promoting the HBV vaccination.

The randomization was executed and the experimental messages and questionnaire were administered by means of an audio computer-assisted self-interview (A-CASI) tool, which is an effective tool particularly for addressing sensitive topics such as STDs (see, e.g., Turner et al. 1998.)

Before participants were exposed to the experimental messages, they were asked a series of questions about their perceptions of two distinct components of product risk: the temporary product risks associated with getting shots (e.g., pain) and the more permanent risks associated with the HBV vaccine (e.g., the possibility that the vaccine might harm their health). Then, following exposure to either gainframed or loss-framed messages, participants were asked about their behavioral intentions regarding the product.

\section{Participants and Procedure}

A total of 213 adult (age 18 years and older) participants were recruited by a trained project manager from the patient populations of the three STD clinics over a period of several months. Participants were screened to ensure that they had no prior self-reported history of HBV infection or vaccination and that they were fluent in English. The sample was $60 \%$ male and had a median age of 27.5 years. Approximately $85 \%$ of the sample had at least a high school diploma or equivalent.

After screening for study eligibility, each participant signed a written informed consent form and then was directed to a private area with a touch-screen notebook computer with headphones. The project manager familiarized the participant in the use of the A-CASI equipment and allowed the participant to complete the interviewing process in private. The project manager had no awareness of either the message treatment group to which participants were randomly assigned or participants' questionnaire responses. 
Before the framing intervention, participants completed a series of questions about demographics, prior behaviors that might affect susceptibility to HBV infection (e.g., sexual behaviors), and perceptions of both the temporary risks of HBV vaccination (e.g., injection pain) and the risks of more permanent negative outcomes (e.g., the possibility that the vaccine itself might cause HBV infection; we discuss these measures in greater depth subsequently). Next, each participant was randomly assigned a message that advocated the adoption of the HBV vaccination that was either gain framed or loss framed. After exposure to the message, participants reported their behavioral intentions.

\section{Stimuli}

The message opened with a gain- (loss-) framed general statement about the consequences of getting (or not getting) the vaccination, followed by two gain- (loss-) framed anecdotes that illustrated these consequences. To increase the perceived personal relevance of the messages, the A-CASI program automatically matched the gender (i.e., names) of the people described in the two anecdotes to the participant's gender; otherwise, the male and female messages were identical. The male version of the message is as follows (the gain-framed version appears in normal text, and the loss-framed language appears in bold):

People who get (don't get) the hepatitis B shot are gaining (losing) a chance to protect themselves and the ones they love.

Michael felt very healthy and didn't believe he would be infected by the Hepatitis B virus, [b]ut he followed (so he didn't follow) the advice of the American Medical Association and got (didn't get) 3 hepatitis $B$ vaccine shots over 6 months. Because of this, he is (not) protected against hepatitis B infection. Now he is much less (much more) likely to get sick or die from serious liver disease, and he can look forward to (may miss out on) a long and healthy life, watching his child grow up.

James decided he needed (didn't need) to protect himself and got (didn't get) the hepatitis B vaccine. As a result, he did not get infected (got infected) after having sex with an infected partner. Because James did not get infected (got infected) with the hepatitis B virus, he did not pass it on (passed it on) to his new partner. So his new partner did not get sick (got sick) with hepatitis B, and now they have gained (lost) a chance for a healthy future together.

We checked this message-framing manipulation in a pretest, in which 38 young adults (average age of 29 years) were randomly assigned either the gain- or the loss-framed message and then responded on Likert scales ( 7 = "strongly agree," 1 = "strongly disagree") to two statements: "This message focuses on the benefits of getting the hepatitis B shot," and "This message focuses on the negative consequences of not getting the hepatitis B shot." As we expected, participants assigned to the gain-framed message condition ( $\mathrm{X}=5.23$ ) were more likely than the participants in the loss-framed message condition $(X=3.25)$ to agree that the message focused on the benefits of compliance $(\mathrm{t}=$ $4.29, p<.001)$. Conversely, participants in the loss-framed message condition $(X=6.25)$ were more likely than participants in the gain-framed message condition $(X=4.23)$ to agree that the message stressed the negative consequences of noncompliance $(\mathrm{t}=3.57, p=.001)$.

\section{Constructs and Measures}

Perceived product risk. Consumers' decisions to get vaccinated are sometimes influenced by their perceptions of two fairly distinct types of product risk. First, there is the perceived risk of temporary pain or discomfort from the needle or injection itself, which sometimes deters consumers from getting vaccinations and other medical procedures involving the use of needles (see, e.g., French and Painter 1994; Zimet et al. 2004). Second, there is the perceived risk of more permanent harm caused by the specific vaccine (e.g., the perceived risk that the vaccine will transmit the disease in question or otherwise cause serious illness or long-term disability; see, e.g., Ball, Evans, and Bostrom 1998).

Before exposure to the framed messages, participants completed a series of measures that assessed these two dimensions of product risk. To assess the perceived risk of shots/needles, participants reported their agreement (on five-point Likert scales) with four items (e.g., "Shots are very painful," "Needles don't bother me at all [reversed]"), which we combined to form a mean scale with a coefficient alpha of .80. To assess perceived risk of the HBV vaccine, participants reported their agreement with six items (e.g., "The vaccine shots for hepatitis can make people very sick," "You can get infected with hepatitis from the hepatitis vaccine shots"), which we combined to form a mean scale with an alpha of .78. As we previously discussed, these two dimensions of perceived product risk appear to be distinct. The two mean scales were not significantly correlated $(\mathrm{r}=$ .098). Furthermore, when all ten items are combined in a factor analysis with an orthogonal rotation, the respective sets of scale items load together on two distinct factors (eigenvalues $>1$ ) with factor loadings between .6 and .9 and minimal cross-loadings (all <.08).

Behavioral intentions. We assessed participants' intentions regarding the $\mathrm{HBV}$ vaccination with three items: a dichotomous yes/no question ("If you were offered the hepatitis B vaccine for free at this clinic, would you get the shot?") and two five-point Likert scale items ("I would recommend that my partner get hepatitis vaccine shots," and "I would recommend that my friends or family members get hepatitis vaccine shots"). These three items were highly intercorrelated and loaded together on a single factor that explained $78 \%$ of their combined variance. Therefore, the three items were all converted to standardized scores (to adjust for scaling differences) and then combined to form a mean scale with a coefficient alpha of .87 .

\section{Results}

We tested $\mathrm{H}_{3}$ to examine whether (as in Study 1) message framing influences the decisional weight that consumers give to temporary product risks. To address this issue, we calculated the correlation between behavioral intention and perceptions of temporary product risk (i.e., risk of short-term injection discomfort), and then we examined whether this correlation differed between the gain- and the loss-framed conditions (see Pietromonaco and Rook 1987). As in Study 
1, this analysis revealed that among participants exposed to loss-framed messages, overall product evaluations were negatively correlated with perceived temporary product risk ( $\mathrm{r}=-.30, p<.01)$. However, among participants exposed to gain-framed messages, overall product evaluations were not significantly correlated with perceived temporary product risk $(\mathrm{r}=-.01, p=.92)$. A Fisher $\mathrm{r}-\mathrm{to}-\mathrm{z}$ transformation (Kleinbaum and Kupper 1978, pp. 106-107) confirmed that the correlation between perceived temporary product risk and overall product evaluation was significantly different across the two framing conditions $(\mathrm{z}=2.18, p<.05)$.

As an additional test of $\mathrm{H}_{3}$, we conducted an ANOVA to examine how framing moderates consumer response to high versus low levels of temporary and permanent product risk. This analysis involved three steps. First, as we noted previously, a factor analysis of the perceived risk items produced two orthogonal factors, one representing perceived temporary product risk (i.e., shot/needle pain) and the other representing perceived permanent product risk (i.e., serious illness caused by the vaccine). Second, we performed a median split on each of these factor scores, which resulted in two uncorrelated dichotomous factors: perceived temporary product risk (high versus low) and perceived permanent product risk (high versus low). Third, we performed a $2 \times$ $2 \times 2$ ANOVA of behavioral intentions, in which message framing (gain versus loss), temporary product risk (high versus low), and permanent product risk (high versus low) were dichotomous factors. This analysis showed significant, negative main effects of both permanent product risk $(\mathrm{F}=$ $25.4, p<.001)$ and temporary product risk $(\mathrm{F}=4.1, p<.05)$ on behavioral intentions. However, consistent with $\mathrm{H}_{3}$, the ANOVA also revealed a significant interaction between framing and temporary product risk $(\mathrm{F}=4.08, p<.05)$. As we hypothesized, perceived temporary product risk had a significant, negative effect on behavioral intentions among loss-framed participants $(\mathrm{F}=6.34, p=.01)$ but had no impact among gain-framed participants $(\mathrm{F}=.09, p=.77)$.

Thus, both the HBV study and the skin cancer experiment, though using different participant populations, settings, and products, produced remarkably similar results: In both studies, participants exposed to loss-framed messages gave considerably more decisional weight to temporary discomfort risk (either skin rash or shot pain) than participants exposed to gain-framed messages. Indeed, gain-framed participants in both studies gave essentially zero decisional weight to such temporary product risks.

Next, we examined $\mathrm{H}_{4}$, that message framing influences the relative weight that consumers give to temporary product risks versus permanent product risks. As we hypothesized, among participants in the loss-framed condition, behavioral intentions were negatively correlated with both perceived temporary product risks $(\mathrm{r}=-.30, p<.01)$ and perceived permanent product risks $(\mathrm{r}=-.35, p<.01)$. To assess the difference between these values, we calculated Meng, Rosenthal, and Rubin's (1992) z statistic. Note that in testing $\mathrm{H}_{3}$, we used the Fisher r-to-z transformation, which is most appropriate for comparing the same correlation across two different samples. However, Meng, Rosenthal, and Rubin's test is most appropriate for comparing the magnitude of two different correlations (e.g., $r_{\text {temprisk,intent }}$ versus $r_{\text {permrisk,intent }}$ ) within the same sample (e.g., lossframed participants), in which each correlation is between a common dependent variable (intention) and alternative predictor variables (temporary risk versus permanent risk). Meng, Rosenthal, and Rubin's test found no significant difference between $r_{\text {temprisk,intent }}$ and $r_{\text {permrisk,intent }}$ among lossframed participants $(\mathrm{z}=.38, p=.70)$, suggesting that lossframed participants give roughly equal weight to permanent versus temporary risks in forming behavioral intentions.

Among gain-framed participants, behavioral intentions were (as we reported previously) uncorrelated with perceived temporary product risks $(\mathrm{r}=-.01)$. However, gainframed participants' behavioral intentions exhibited a strong negative correlation $(\mathrm{r}=-.47, p<.0001)$ with perceived permanent product risks. Meng, Rosenthal, and Rubin's (1992) test indicates that the difference between these two correlations was statistically significant $(\mathrm{z}=4.03, p<.0001)$.

Thus, as we predicted in $\mathrm{H}_{4}$, consumers exposed to gain-framed messages appear to give significantly more decisional weight to permanent product risks than to temporary product risks. In contrast, consumers exposed to lossframed messages respond equally negatively to both types of product risk.

\section{Discussion}

Consumers are increasingly called on to evaluate product risk (i.e., the possibility that product use may cause negative consequences). However, there has been relatively little research on how consumers evaluate product risk information, and the research that exists has produced contradictory findings. To help explain these contradictory findings, we hypothesized that the persuasive effects of product risk information may be moderated by message framing. Specifically, we evaluated three competing theories of how framing and product risk may interact to influence consumer product evaluations and intentions.

We evaluated function/risk theory (Meyerowitz and Chaiken 1987; Rothman and Salovey 1997), which posits that (1) loss-framed messages induce risk-seeking behavior, whereas gain-framed messages induce risk-avoidance behavior; (2) consumers perceive detection behaviors as risky and prevention behaviors as low risk (or "safe"); and (3) loss-framed messages increase consumers' motivation to use detection products, whereas gain-framed messages increase consumers' motivation to use prevention products.

None of these three premises was supported by our data. First, although manipulation checks confirmed that consumers understood the respective functions (detection versus prevention) of the two product concepts presented in Study 1, participants did not perceive the detection product as inherently riskier than a prevention product with the same form and usage experience. Second, Study 1 did not find any difference in message-framing effects between detection and prevention products. Third, function/risk theory's most basic premise, that loss-framed messages induce risk-seeking behavior, was contradicted by both Studies 1 and 2. In both experiments, participants exposed to loss-framed messages exhibited a general aversion to product risk involving both relatively short-term adverse 
effects (Studies 1 and 2) and more permanent harm (Study 2). There was no evidence of risk-seeking behavior among loss-framed participants in either experiment.

As we noted previously, proponents of function/risk theory claim that their hypothesis of risk seeking among people exposed to loss-framed messages is grounded in Tversky and Kahneman's (1981) prospect theory. In that case, does our empirical disconfirmation of this hypothesis mean that prospect theory is wrong? Absolutely not. It simply means that in the attempt to derive function/risk theory from prospect theory, key aspects of prospect theory (particularly the meaning of the word "risk") were lost in translation. As we noted previously, Tversky and Kahneman used the word "risk" in a technical sense to mean the variance of potential outcomes, so that a riskier option entails both extremely positive and extremely negative possibilities rather than a predictable (but mediocre) certain option. When risk is operationalized in this way, participants are sometimes motivated to choose the risky option because of its positive possibilities. This is particularly true if outcomes are framed as losses because the certain option then entails a certain small loss, whereas the risky option offers the upside possibility of no loss. Given this somewhat esoteric definition of "risk," risk-seeking behavior seems plausible.

However, although this "risk as variance" definition is used in a few academic fields, including expected utility theory (the point of departure for prospect theory) and financial investment analysis, it does not match the way the word "risk" is used by function/risk theorists or, for that matter, in most academic disciplines. To most people, academic or layman, "risk" specifically connotes the possibility of something bad. For example, Merriam-Webster (2005) defines risk as "possibility of loss or injury: peril." Similarly, in a typical consumer behavior definition, Solomon (2004, p. 304) defines perceived risk as "the belief that the product has potentially negative consequences," and risk perception researcher Paul Slovic (2000) uses the words "risk" and "hazard" interchangeably. In none of these cases does "risk" imply the possibility of extremely positive consequences that help explain Tversky and Kahneman's (1981) results.

Therefore, to understand how message framing might influence consumers' responses to product risk (defined as potential negative consequences), we proposed two alternative theories: valence congruity theory and risk discrimination theory. Both theories are based on prior findings that message framing influences mood and that mood influences consumers' responses to risk. Both theories suggest that exposure to gain-framed messages increases consumers' tolerance for temporary product risks, a finding that was confirmed in both Study 1 and Study 2. However, the theories diverge in predicting how message framing will affect consumers' responses to more serious, long-lasting product risks. Thus, Study 2 was designed to address this issue. The findings of this experiment support risk discrimination theory: Participants exposed to gain-framed messages appear to be better able to discriminate between important and unimportant risks; they essentially ignore minor or temporary product risks but exhibit considerable caution regarding the possibility of more permanent, serious risks.
In addition to their theoretical implications, our findings may have implications for those who design and regulate promotional messages for risky products, including DTC advertisements for prescription drugs. Food and Drug Administration requirements dictate that any DTC advertisement that mentions a product's brand name (e.g., Levitra) and its benefits (improving male sexual function) must disclose the product's side-effect risks (e.g., severe headaches). The only way to avoid such disclosure is to either not name the product (e.g., "Ask your doctor about new treatments for erectile dysfunction") or not say what it does (e.g., "Ask your doctor about Levitra"). Thus, DTC advertisers must either mention product risks or produce rather cryptic advertisements (e.g., the Levitra advertisement that does not indicate what it does but shows a football going through a swinging tire).

Although there has been relatively little research on how consumers process such product risk information, there are several theories. One theory (e.g., Goetzl 2000; Rodale Publications 1999) is that product risk disclosures actually enhance advertisement credibility by making the advertiser seem more forthcoming. Another theory is that product risk disclosures undermine the positive content of an advertisement and reduce advertising persuasiveness (Goetzl 2001; Morris, Mazis, and Brinberg 1989). However, our findings do not support either of these simple main effects of product risk. Instead, our data suggest that consumers respond differently to product risk depending on both the nature of this risk (temporary versus permanent) and the framing of the persuasive message. Participants exposed to loss-framed messages exhibited an aversion to product risk, whereas those exposed to upbeat, gain-framed messages essentially disregarded temporary product risks in forming product evaluations and intentions.

These results suggest that advertisers are able to reduce the decisional weight that consumers give to certain types of product risk information by placing such information in the context of upbeat, gain-framed message executions. If confirmed by further research, this finding has potentially important implications both for marketers required to include product risk disclosures in their promotional materials and for the consumer protection agencies that institute these disclosure requirements.

To understand the policy implications of these findings more fully, further research should explore several issues. Specifically, further research should examine whether the framing-induced optimism we observed in our study is beneficial or harmful in general to consumer welfare. As we noted previously, our research found that consumers exposed to gain-framed messages gave essentially zero weight to temporary product risks (i.e., skin rash or shot pain) in evaluating a disease protection product (i.e., skin cancer lotion or hepatitis vaccination). However, is this disregard of temporary product risk a good thing or a bad thing? On the one hand, in general, consumers should consider risks before pursuing any course of action. On the other hand, perhaps consumers should give the possibility of a skin rash (or a sore shoulder) considerably less weight than the chance to protect themselves from skin cancer or liver disease. Perhaps optimism induced by gain-framed 
messages simply helps consumers overcome their natural hesitancy toward taking calculated risks (i.e., the omission bias). This is an important issue for further research.

Finally, further research should explore the emotional effects of message framing, examining more broadly how these effects may influence consumer judgment and decision making. As we noted previously, most messageframing research to date has been grounded (at least ostensibly) in Kahneman and Tversky's (1979; see also Tversky and Kahneman 1981) prospect theory, which, as is the case with much of behavioral decision theory, tends to emphasize cognitive over affective phenomena (for a discussion of the neglect of emotion in behavioral decision research, see, e.g., Loewenstein et al. 2001). However, the finding that message framing influences consumers' moods, along with the wealth of research showing that mood affects decision making (e.g., Isen 2000), could open up entirely new avenues in the study of framing effects. We strongly encourage researchers to explore those avenues.

\section{Appendix Examples of Experimental Messages}

\section{Detection/Low Risk/Loss}

Skin cancer is the most common form of cancer among people in their twenties. Every 53 minutes, someone dies of skin cancer. Skin cancer can be hard to see with the naked eye or may look like a normal mole or freckle.

Fortunately, there is now a medicated lotion which can detect skin cancer. This product is not a sunblock or sun- screen. It is applied by a doctor to the patient's skin and creates a gentle reaction, which allows the doctor to easily detect the early development of skin cancer. This lotion is highly effective and very safe.

If you fail to use this lotion, you will be losing an opportunity to detect the development of skin cancer cells before they can do serious harm. By failing to use this lotion, you can significantly harm your chances of living a long, cancer-free life.

For more information, call 1-800-4CANCER, or talk to your doctor.

\section{Prevention/High Risk/Gain}

Skin cancer is the most common form of cancer among people in their twenties. Every 53 minutes, someone dies of skin cancer. Skin cancer can be hard to see with the naked eye or may look like a normal mole or freckle.

Fortunately, there is now a medicated lotion which can prevent skin cancer. This product is not a sunblock or sunscreen. It is applied by a doctor to the patient's skin and creates a gentle reaction, which allows the doctor to easily prevent the early development of skin cancer. This lotion is highly effective and generally safe. However, in some patients, it can cause a severe skin rash lasting several weeks.

If you use this lotion, you will be gaining an opportunity to prevent the development of skin cancer cells before they can do serious harm. By using this lotion, you can significantly improve your chances of living a long, cancerfree life.

For more information, call 1-800-4CANCER, or talk to your doctor.

\section{REFERENCES}

Adaval, Rashmi (2001), "Sometimes It Just Feels Right: The Differential Weighting of Affect-Consistent and AffectInconsistent Product Information," Journal of Consumer Research, 28 (June), 1-17.

American Cancer Society (2004), "Skin Cancer Facts," (accessed November 10, 2004), [available at www.cancer.org/docroot/ PED/content/ped_7_1_What_You_Need_To_Know_About_ Skin_Cancer.asp?sitearea=PED].

Arkes, Hal (2004), "The Psychology of Patient Decision Making: Framing," in Interactive Textbook of Clinical Symptom Research, (accessed December 2, 2004), [available at http:// symptomresearch.nih.gov/chapter_4/sec1/chas1pag1.htm].

Ball, Leslie, Geoffrey Evans, and Ann Bostrom (1998), "Risky Business: Challenges in Vaccine Risk Communication," Pediatrics, 101 (3), 453-58.

Baron, Reuben and David A. Kenny (1986), "The ModeratorMediator Distinction in Social Psychological Research: Conceptual, Strategic and Statistical Considerations," Journal of Personality and Social Psychology, 51 (6), 1173-82.

Blanton, Hart, R. Vanden Eijnden, B. Buunk, F. Gibbons, M. Gerrard, and A. Bakker (2001), "Accentuate the Negative: Social Images in the Prediction and Promotion of Condom Use," Journal of Applied Social Psychology, 31 (2), 274-95.

Calfee, John (2002), "Public Policy Issues in Direct-to-Consumer Advertising of Prescription Drugs," Journal of Public Policy \& Marketing, 21 (Fall), 174-93.
Centers for Disease Control and Prevention (1995), "Improving Influenza Vaccination Rates for Medicare Beneficiaries: Montana and Wyoming," Morbidity and Mortality Weekly Report. Washington, DC: U.S. Department of Health and Human Services.

Cohen, Joel (2002), "Introductory Comments: Direct-toConsumer Prescription Drug Advertising: Evaluating Regulatory Policy in the United States and New Zealand," Journal of Public Policy \& Marketing, 21 (Fall), 172-73.

Cox, Dena and Anthony D. Cox (2001), "Communicating the Consequences of Early Detection: The Role of Evidence and Framing," Journal of Marketing, 65 (July), 91-103.

Darroch, Jacqueline and Jennifer Frost (1999), "Women's Interest in Vaginal Microbicides," Family Planning Perspectives, 31 (February), 16-23.

Deldin, Patricia and Irwin B. Levin (1986), "The Effect of Mood Induction in a Risky Decision-Making Task," Bulletin of the Psychonomic Society, 24 (1), 4-6.

Ferguson, Eamonn, Peter Bibby, Joanna Leaviss, and Andrew Weyman (2003), Effective Design of Workplace Risk Communication, (accessed December 2, 2004), [available at www.hse. gov.uk/research/rrpdf/rr093.pdf].

Fitch, Malcolm (1997), "What You Can Really Learn from Fund Performance," Money, (March), B1-B4.

Fox, Richard, Dean Krugman, James Fletcher, and Paul Fisher (1998), "Adolescents' Attention to Beer and Cigarette Print Ads 
and Associated Product Warnings," Journal of Advertising, 27 (Fall), 57-67.

French, Gina and Eileen Painter (1994), "Blowing Away Shot Pain: A Technique for Pain Management During Immunization," Pediatrics, 93 (3), 384-88.

Goetzl, David (2000), "TVB Study: DTC Disclosures Lend Credibility to Drug Ads," Advertising Age, (June 5), 6.

___ (2001), "Xenical Reworks Its Ads; TV Spots Stress Awareness, Skip Over Side Effects," Advertising Age, (February 5), 3 .

Homer, Pamela and Sun-Gil Yoon (1992), "Message Framing and the Interrelationships Among Ad-Based Feelings, Affect and Cognition," Journal of Advertising, 21 (March), 19-32.

Howard, Daniel, Charles Gengler, and Ambuj Jain (1995), "What's in a Name? A Complimentary Means of Persuasion," Journal of Consumer Research, 22 (September), 200-211.

Isen, Alice (2000), "Positive Affect and Decision Making," in Handbook of Emotion, M. Lewis and J. Haviland-Jones, eds. New York: Guilford, 417-35.

- and Nehemia Geva (1987), "The Influence of Positive Affect on Acceptable Level of Risk: The Person with a Large Canoe Has a Large Worry," Organizational Behavior and Human Decision Processes, 39 (April), 145-54.

Kahneman, Daniel and Amos Tversky (1979), "Prospect Theory: An Analysis of Decision Under Risk," Econometrica, 47 (2), 263-91.

Keppel, Geoffrey (1982), Design and Analysis. Englewood Cliffs, NJ: Prentice Hall.

Kleinbaum, David and Lawrence Kupper (1978), Applied Regression Analysis and Other Mutivariable Methods. North Scituate, MA: Duxbury Press.

Krugman, S. and C. Stevens (1994), "Hepatitis B Vaccine," in Vaccines, S. Plotkin and E. Mortimer, eds. Philadelphia: W.B. Saunders, 419-37.

Leith, Karen and Roy Baumeister (1996), "Why Do Bad Moods Increase Self-Defeating Behavior? Emotion, Risk-Taking and Self-Regulation," Journal of Personality and Social Psychology, 71 (6), 1250-67.

Levin, Irwin, Sandra Schneider, and Gary Gaeth (1998), "All Frames Are Not Created Equal: A Typology and Critical Analysis of Framing Effects," Organizational Behavior and Human Decision Processes, 76 (November), 149-88.

Loewenstein, G., E. Weber, C. Hsee, and N. Welch (2001), "Risks as Feelings," Psychological Bulletin, 127 (2), 267-86.

McCaul, Kevin, Ann Branstetter, Dawn Schroeder, and Russell Glasgow (1996), "What Is the Relationship Between Breast Cancer Risk and Mammography Screening? A Meta-Analytic Review," Health Psychology, 15 (6), 423-29.

Meng, Xiao-Li, Robert Rosenthal, and Donald Rubin (1992), "Comparing Correlated Correlation Coefficients," Psychological Bulletin, 111 (3), 172-75.

Menon, Ajit, Aparna Deshpande, Matthew Perri, and George Zinkhan (2003a), "Communicating Risk Information in Print Direct-to-Consumer Prescription Drug Advertisements: Implications for Public Health," paper presented at the 131st American Public Health Association Annual Meeting and Exposition, San Francisco (November 15-19), (accessed December 2, 2004), [available at http://alpha.confex.com/apha/131am/ techprogram/paper_58577.htm].

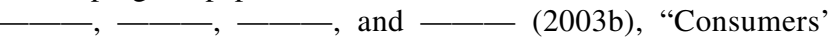
Attention to the Brief Summary in Print Direct-to-Consumer Advertisements: Perceived Usefulness in Patient-Physician Discussions," Journal of Public Policy \& Marketing, 22 (Fall), 181-91.

Merriam-Webster (2005), Merriam-Webster Online Dictionary, (accessed May 1, 2005), [available at http://www.m-w.com/ cgi-bin/dictionary?book=Dictionary $\& v a=r i s k \& x=13 \& y=14]$.
Meyerowitz, Beth and Shelley Chaiken (1987), "The Effort of Message Framing on BSE Attitudes, Intentions and Behavior," Journal of Personality and Social Psychology, 52 (3), 500-510.

Morris, Louis, Michael Mazis, and David Brinberg (1989), "Risk Disclosures in Televised Prescription Drug Advertising to Consumers," Journal of Public Policy \& Marketing, 8 (Spring), 64-70.

Perdue, Barbara and John O. Summers (1986), "Checking the Success of Manipulations in Marketing Experiments," Journal of Marketing Research, 23 (November), 317-26.

Pietromonaco, P. and K. Rook (1987), "Decision Style in Depression: The Contribution of Perceived Risks and Benefits," Journal of Personality and Social Psychology, 52 (2), 399-408.

Robberson, M.R. and R.W. Rogers (1988), "Beyond Fear Appeals: Negative and Positive Persuasive Appeals to Health and SelfEsteem," Journal of Applied Social Psychology, 13 (March), 277-87.

Rodale Publications (1999), Prevention Magazine: A National Survey of Consumer Reactions to Direct-to-Consumer Advertising. Emmaus, PA: Rodale Publications.

Rothman, Alexander J., Steven C. Martino, Brian T. Bedell, Jerusha B. Detweiler, and Peter Salovey (1999), "The Systematic Influence of Gain- and Loss-Framed Messages on Interest in and Use of Different Types of Health Behavior," Personality and Social Psychology Bulletin, 25 (November), 1355-69.

and Peter Salovey (1997), "Shaping Perception to Motivate Healthy Behavior: The Role of Message Framing," Psychological Bulletin, 121 (January), 3-19.

-, Carol Antone, Kelli Keough, and Chloe Martin (1993), "The Influence of Message Framing on Intentions to Perform Health Behaviors," Journal of Experimental Social Psychology, 28 (September), 408-433.

Slovic, Paul (2000), The Perception of Risk. London: Earthscan.

Sobel, Michael E. (1982), "Asymptotic Confidence Intervals for Indirect Effects in Structural Equation Models," Sociological Methodology, 13, 290-312.

Solomon, Michael (2004), Consumer Behavior. Upper Saddle River, NJ: Pearson/Prentice Hall.

Thomaselli, Rich (2004), "Marketers Left in Limbo by DTC Delay," Advertising Age, (September 20), 3.

Thomson (2004), Science Citation Index Expanded, (accessed December 2, 2004), [available at http://www.isinet.com/ products/citation/scie/].

Thorsteinson, Todd and Scott Highhouse (2003), "Effects of Goal Framing in Job Advertisements on Organizational Attractiveness," Journal of Applied Social Psychology, 31 (11), 2393-2412.

Turner, C., L. Ku, S. Rogers, L. Lindberg, J. Pleck, and F. Sonenstein (1998), "Adolescent Sexual Behavior, Drug Use and Violence: Increased Reporting with Computer Survey Technology," Science, (March 8), 867-73.

Tversky, Amos and Daniel Kahneman (1981), "The Framing of Decisions and the Psychology of Choice," Science, 211 (January), 453-58.

Vastfjall, Daniel (2002), "Influences of Current Mood and Noise Sensitivity on Judgments of Noise Annoyance," Journal of Psychology, 136 (July), 357-70.

Weinstock, H., G. Bolan, J. Moran, T. Peterman, L. Polish, and A. Reingold (1995), "Routine Hepatitis B Vaccination in a Clinic for Sexually Transmitted Diseases," American Journal of Public Health, 85 (June), 846-49.

Yuen, K. and T. Lee (2003), "Could Mood State Affect RiskTaking Decisions?" Journal of Affective Disorders, 75 (1), 11-18.

Zimet, G., S. Rosenthal, J.D. Fortenberry, R. Brady, W. Tu, J. Wu, D. Bernstein, L. Stanberry, K. Stone, K. Fife, and J. Leichliter (2004), "Factors Predicting the Acceptance of Herpes Simplex Virus Type 2 Antibody Testing," Sexually Transmitted Diseases, 31 (11), 665-69. 